\title{
The Effect of Using Simulation-Based Learning on Nursing Performances of Early Postpartum Hemorrhage in Nursing Students
}

\author{
Kornkarn Pansuwan*®, Sirikanok Klankhajhon® \\ Faculty of Nursing, Naresuan University, Phitsanulok, Thailand
}

\begin{abstract}
Background: Early posypartum haemorrhage (PPH) is a crucial problem in maternal and newborn care. The simulation-based learning has an important role to improve knowledge, practical skills, and attitude in realistic casebased scenarios.

Purpose: This study aims to examine the effect on using simulated scenario in the simulation laboratory on nursing performance of early postpartum hemorrhage of nursing students.

Methods: The quasi-experimental research, one group pretest-posttest design was used to study with the nursing students from the Faculty of Nursing, Naresuan University in Academic Year 2019 during the period of December 1, 2019 to January 31,2020 . The subjects of thirty nursing students were selected by purposive sampling. The instruments were the the ability in nursing of early postpartum hemorrhage through the questionnaires which consists of the performance test and satisfaction before and after the early PPH simulation program. The content of scenario consists of the definition, etiology, risk factors, signa and symptoms, treatment, holistic nursing care, and continuous care. The data were analysed as the descriptive: numbers, percentages, frequency, mean and standard deviation. The paired t-test was used to compare the outcome between pre-test and post-test.

Results: The data were analysed by t-test. The results illustrated that the students who learned through simulated scenario on performance in nursing care of women with early postpartum hemorrhage had, after learning, higher performance in nursing care of women with early postpartum hemorrhage than that before learning at the .01 level of significance. The students were satisfied learning by using the simulation program in the high level $(\bar{x}=4.26$, S.D. = 0.54).

Conclusion: The simulation-based learning improves the core competencies and performances of nursing students for management women with early postpartum hemorrhage as knowledge, potential clinical care skills, and attitude. It will be useful to implement for nursing care women regarding early postpartum hemorrhage in the real situations.
\end{abstract}

Gopen access

Jurnal Keperawatan
Padjadjaran (JKP)

Volume 9(3), 175-180

(C) The Author(s) 2021

http://dx.doi.org/ 10.24198/jkp.

v9i3.1682

Article Info

Received : August 06, 2021

Revised : October 05, 2021

Accepted : October 13, 2021

Published : December 08, 2021

Corresponding author

Kornkarn Pansuwan

Assistant Professor at Faculty

of Nursing, Naresuan University,

Phitsanulok 65000, Thailand,

Phone: +66 55961640, E-mail:

kornkarnpansuwan@gmail.com

Citation

Pansuwan, K., \& Klankhajhon, S. (2021). The Effect of Using Simulation-Based Learning on Nursing Performances of Early Postpartum Hemorrhage in Nursing Students. Jurnal Keperawatan Padjadjaran, 9(3), 175-180.

https://doi.org/ 10.24198/jkp. v9i3.1682

\section{Website}

http://jkp.fkep.unpad.ac.id/index. php/jkp

This is an Open Access article distributed under the terms of the Creative Commons Attribution-NonCommercial 4.0 International License.

E-ISSN: 2442-7276

P-ISSN: 2338-5324
Keywords: nursing; postpartum hemorrhage; simulation-based learning; simulated scenario.

\section{Introduction}

Early posypartum haemorrhage (PPH) is definded as blood loss of 500 millilitres $(\mathrm{ml}$.) or more within 24 hours at the after vaginal delivery or at least $1,000 \mathrm{ml}$. or more than caesarean delivery. Most of PPH majority result from uterine atony around sixty percentages, and then vaginal and perineal trauma, retained placenta, and disseminated intravascular coagulation (DIC) respectively. Time, within 24 hours after childbirth, is an important role in management of PPH in term of assessment, implementation, prevention, and evaluation (Suprasert, Cheewakriangkrai, Tongprasert \& Pansri, 2015). Early PPH is a leading cause of maternal mortality globally including in Thailand as hypovolemic shock. It is also leading cause of hysterectomy 


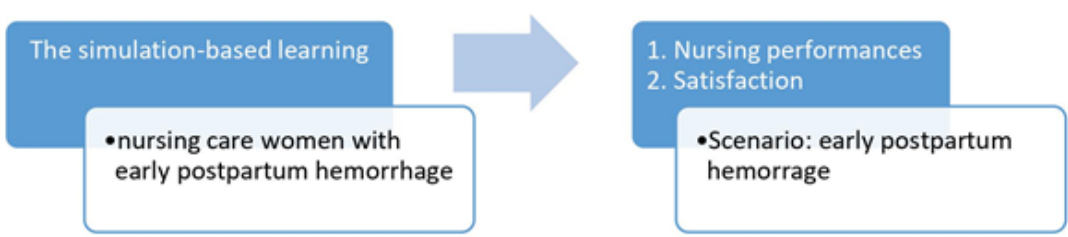

Figure 1. Conseptual Framework

after PPH that impact on increase rate of low selfesteem in women. The World Health Organization (WHO) recommendations have supported a critical intervention for PPH prevention as Active Management of Third Stage of Labour (AMTSL). It is consisted of three steps: administration of uterotonic, preferably oxytocin, immediately after delivery the baby; controlled cord traction (CCT) to delivery the placenta; and massage of uterine fundus after delivered placenta. This intervention has strongly evidenced to prevent and reduce rate of $\mathrm{PPH}$ (WHO, 2012). Nurse is a key person for assessment the risk factors, prevention, and management $\mathrm{PPH}$ (Sansiriphun \& Baosoung, 2017).

The learning and teaching process in nursing aim to improve competencies of nursing care and clinical decision making that is a potential outcome-based and learning achievement in nursing education (Glynn, 2012). Simulation based learning is learning method and strategy to develop knowledge, attitude, and practical skills that facilitates the effective learning in realistic case-based scenarios as computer games, role-play situations, and SimMom in simulation laboratory. This strategy has supported to develop core competencies as follows: problems solving, managing common conditions and clinical care, accessing and using information for making decision, self-regulation and evaluation, caring and confident approach. The components of simulation-based learning design are devided in six steps: 1) problem identification and general needs assessment; 2) targeted needs assessment; 3) goals and measurable objectives; 4) educational strategies; 5) Implementation; and 6) Evaluation and feedback. This simulation-based learning impacts directly on learner performances following the circle of learning as knowledge acquisition, skills proficiency, decision making, simulation in teams, and clinical experiences respectively. It also indirect impacts on time, flexibility, confidence, and safety of patients in the real-life situations (Kanhadilok \& Punsumreung, 2016). The study showed that the learning achievement of the simulation-based scenarios were significant related with higher competencies of communication, simulation in teams, management in critical care, analytical thinking, leadership, and rational nursing care complexity in nursing students (Lewis, Strachan, \& Smith, 2012) especially in the COVID 19 pandemic.

Therefore, the aim of this study was to examine the effect on using simulated scenario on nursing performance of early postpartum hemorrhage and satisfaction of nursing students that improve the core competencies and performances of nursing students for management women with early postpartum hemorrhage as knowledge, potential clinical care skills, attitude, and implementing the real situations.

\section{Conceptual of framework}

In this study, the simulation-based learning was designed for nursing care women with early postpartum hemorrhage to enhance and integrate knowledge and practical skills in real-life situations including improving attitude and core nursing competencies and performances.

\section{Research Hypothesis}

1. Performances of nursing students for early postpartum hemorrhage after the simulationbased learning: stimulated scenario in simulation laboratory have significantly higher than before the intervention.

2. The simulation-based learning enhances the satisfaction of nursing students.

\section{Methods}

The quasi-experimental design was used based on the one group pre-test and post-test on the nursing performances of the nursing students. This study was conducted at the Faculty of Nursing, Naresuan University, Thailand over three months during the period of December 1, 2019 to January 31, 2020, Academic Year 2019. Ethical approval for the study was obtained from the Naresuan University Institutional Review Board (COA no 509/2019), Naresuan University, Thailand, dated on September 24,2019 . The decision to participate was made by individual students independently and without pressure. Nursing students could withdraw any time without giving any reason and their withdrawal from the research did not affect the learning and teaching process. All data in this study were identified by individual codes, except for copies of the consent form which contained the names and contact details of all participants. No data could be accessed by anyone other than the researcher, co-researcher and consultant. The data were presented and reported without personal identification. During data collection and analysis, the researcher used a computer with strong password protection. All files and documents were kept securely in the locked storage at Naresuan University, Thailand. Personal information will be kept for one year after the end of the study. All of process of this study processed following the protocol of the Naresuan University Institutional Review Board. 
Table 1. The learning outcomes of the participants $(n=30)$

\begin{tabular}{lcccccc}
\hline \multicolumn{1}{c}{ Performance test } & $\mathbf{M}$ & SD & $\mathbf{t}$ & $\mathbf{d f}$ & $\mathbf{p}$ & $\mathbf{d}$ \\
\hline Pre-test & 19.60 & 1.658 & & & & \\
& & & 12.428 & 29 & 0.000 & 4.67 \\
Post-test & 24.27 & 2.020 & & & & \\
\hline
\end{tabular}

Table 2: The satisfaction on the simulation program: nursing care women with early PPH

\begin{tabular}{|c|c|c|c|}
\hline Items $(n=30)$ & Mean & SD & Level \\
\hline The learning satisfaction (Overview) & 4.26 & 0.54 & High \\
\hline $\begin{array}{l}\text { (1) The orientation of the simulation program is clear and easy to } \\
\text { understand }\end{array}$ & 4.22 & 0.54 & High \\
\hline (2) The hirachy of learning activity are appropriate & 3.94 & 0.57 & High \\
\hline (3) Appropriate time for learning activity & 3.85 & 0.62 & High \\
\hline (4) Learners participate in the learning process & 4.67 & 0.56 & Highest \\
\hline (5) Learners engage in the learning activities & 4.58 & 0.51 & Highest \\
\hline $\begin{array}{l}\text { (6) Give an opportunity to express learner's opinions and collabo- } \\
\text { rate with team }\end{array}$ & 4.12 & 0.48 & High \\
\hline (7) Support learner as an active learning & 4.02 & 0.50 & High \\
\hline (8) Enhance knowledge and practical skills & 4.08 & 0.63 & High \\
\hline $\begin{array}{l}\text { (9) Appropriate and modern materials for simulation-based learn- } \\
\text { ing }\end{array}$ & 4.55 & 0.49 & Highest \\
\hline (10) Positive larning environment & 4.52 & 0.48 & Highest \\
\hline
\end{tabular}

Thirty nursing students were selected by purposive sampling from 113 nursing students of the fourth year, Faculty of Nursing, Naresuan University, Thailand. Browne (1995) suggests that the sample size for the quasi-experimental design should be at least thirty subjects. It will be normal distributed. An estimate of the population standard deviation sufficient to achieve in the trials (Browne, 1995; Lancaster, Dodd, \& Williamson, 2004). The participants were screened through inclusion and exclusion criteria. Inclusion criteria are student who express willingness to participate in the study. Grade point average (GPA) is considered, which determined to academic and performance skills. Students who had 1) excellent in academic (GPA 3.50-4.00), 2) good (GPA 2.50-3.49), and 3) satisfactory (GPA 2.00-2.49) were included in this study over ten students/group. Students who had got GPA $<2.00$ were excluded.

The simulation program: stimulated scenario about early postpartum hemorrhage was designed and developed by the researcher team. The scenario was conducted based on the content of nursing care during delivery and women with early postpartum hemorrhage; interactive learning; and simulation program development between behaviors, environment, and personal factors as follows: 1) a specific objective, 2) level of fidelity, 3) problem solving, 4) student support, and 5) reflective thinking (Rothgeb, 2008; Dleikan, Lakissian, Hani, \& Sharar-Chami, 2020). The content of early postpartum hemorrhage scenario consists of the definition, etiology, risk factors, signa and symptoms, treatment, holistic nursing care, and continuous care. The contents were designed based on the evidences of nursing care of women with early postpartum hemorrhage (Who, 2012; Suprasert, Cheewakriangkrai, Tongprasert \& Pansri, 2015; Sansiriphun \& Baosoung, 2017; Murray \& McKinny, 2019). The scenario was accuracy checked and tested by the three consultants, who is an expert in maternal and newborn nursing and midwifery.

The performance test, which consisted of communication, teams, management in critical care, analytical thinking, leadership, and rational nursing care complexity as knowledge, attitude, practical skills in nursing care of women with early postpartum hemorrhage, was conducted by the reascher team as a modified essay questions following the scenario with consists of fifteen items as a score from zero to two score: 0 was mean totally wrong, 1 was mean partially wrong and partially right, and 2 was mean totally right. The satisfaction questionnaire was designed by the reascher team for ten items as a rating scale from zero to five score: 0 was mean I really disagree with this item and 5 was mean I really agree with this item. All the questionnaires were tested the reliability with the thirty nursing students through a Kuder-Richardson (KR-20) at 0.88 and 0.91 respectively. The content validity was proved through the three experts based on the index of concurrence (IOC) at 0.8-1.0 and 0.7-1.0 respectively.

The data were collected from the thirty nursing students at the Faculty of Nursing, Naresuan University, Thailand through the questionnaires 
which consists of the performance test and satisfaction of the simulation-based learning. Baseline measures through performane test was collected before starting the simulated scenario as a pre-test over thirty minutes. The learning outcomes data through the performance test around thirty minutes and satisfaction around fifteen minutes after the completion of the simulated scenario. The simulation program was proceeded as follows: 1) spilt students into six groups, five students in each group, 2) pre-brief about scenario around fifteen minutes, 3) role-play with SimMom in the simulation laboratory around thirty minutes, 4) debrief with the team around fifteen minutes, and 5) reflective feedback around fifteen minutes.

The data were analysed by using SPSS for Windows version 24.0 (IBM Corp, 2016). A two-tailed statistical evaluation of the study was performed with an alpha of 0.05 as the cut off for significance (Eldridge et al., 2016). The data were reported as the descriptive: numbers, percentages, frequency, mean and standard deviation. The paired t-test was used to compare the outcome between pre-test and post-test. The assumptions were checked normally as a distributed continuous variable by the researher (Field, 2015).

\section{Results}

The samples, thirty nursing students of the fourth years from the Faculty of Nursing, Naresuan University, Thailand, were invited to participate in this study. A total of thirty nursing students were participated in this simulation program and completion the questionnaires (100\%). The sample was aged between 22 and 24 years. The mean (M) sample age was 22.40 years with standard deviation (SD) of 1.22 years. The performance in nursing care of women with early postpartum hemorrhage after study were higher than the before study significantly $(p=0.000)$. The sample demonstrated improvement across all performance test after the completion of the simulated scenario in term of knowledge, attitude, practical skills in nursing care of women with early postpartum hemorrhage which had an average score 19.60 and 24.27 scores respectively (Table 1).

The sample showed their satisfaction about experiences of the simulation program: nursing care of women with early postpartum hemorrhage scenario was high level (Table 2). The highest four items were illustrated as learners participate in the learning process, learners engage in the learning activities, and appropriate, modern materials for simulation-based learning, and positive learning environment.

In addition, the samples expressed their experiences that help to gain their knowledge, practical skills, and self-confidence in nursing care for women with early postpartum hemorrhage. They indicated that they enhance the skills in assessment, psychomotor activity, critical thinking, problem solving, decision making, collaboration with their teams when they engaged in this study through participation, observation, debriefing, and reflection. They also indicated they feel safe to learn and practice with nursing care scenario before practice in the real situation.

\section{Discussion}

This study demonstrated the simulation-based learning through the simulated scenario supported the learner to get higher score on the performance in nursing care women with early postpartum hemorrhage as the learning achievement. The performance of the participants after study the simulation program were significantly higher than before the study. The samples indicated their learning improvement as knowledge, attitude, practical skills in nursing care of women with early postpartum hemorrhage including the skills in assessment, psychomotor activity, critical thinking, problem solving, decision making, collaboration team, and self-confidence. The findings were consistent related with the studies on the learning achievement through the simulation-based learning. These studies were found the learners enhance their understanding, knowledge, skills, and selfpractice in their issues in the simulation laboratory. It also gained their knowledge, practical skills, performances, and applying in the real situation. It is very useful to improve attitude, knowledge, capability, competencies, and practical skills in nursig care. Several studies illustrated the success rate of learning performances on the simulated scenario was associated with the high level of selfconfidence, that related with high self-efficacy in term of knowledge and practical skills in nursing care including the critical thinking, problem solving, and decision making. The benefits of simulated based learing supported the learners to increase collaboration with orthers, positive observation, debriefing, and self-reflective thinking (Rothgeb, 2008; Khemmani, 2014; Dleikan, Lakissian, Hani, \& Sharar-Chami, 2020).

The findings were consistent related with the study of Sinthuchai and Ubolwan (2017) that studied the effect of simulation-based learning on knowledge, satisfaction, and self-confidence of nursing students in the fourth year. The study found that after the intervention, the students get higher score of knowledge and self-confidence including the satisfaction than before of the study significantly (Sinthuchai \& Ubolwan, 2017). This finding supported the benefits of the simulationbased learning through the simulated scenario in the simulation laboratory for nursing students. It showed that gained their knowledge and self-confidence in realistic case-based scenario before practice in the real situation and working in the future.

The simulation-based learning through the nursing care scenario as virtual reality processed in three stages as follows: 1) pre-brief phase that 
preparing the students for make an understanding the process of the realistic case-based learning, simulation model, materials, and simulated scenario; 2) simulated clinical experience (SCE) phase that phase of practice in the virtual reality following the simulated scenario. This phase focuses to develop the knowledge, critical thinking, decision making, and team working of the students. The instructors take role as a facilitator in term of academic assessment, observation, and feedback to the students.; and 3) debriefing phase that is the most important in the simulation-based learning. This stage supports the learner to improve their knowledge, attitude, and nursing skills through slefreflection and self-evaluation. All of the processes facilitate the learner to develop their knowledge and practical skills for integration nursing care in the real situation (Mahaprom, Chatrung, Noparoojjinda, Peawnalaw, \& Doungkeaw, 2019).

The participants expressed their high satisfaction of the simulation program in term of learners participate in the learning process, learners engage in the learning activities, and appropriate, modern materials for simulation-based learning, and positive learning environment. It might be useful for nursing care at the real situation and work in the future. The participants also showed their experiences that they enhance the skills in assessment, psychomotor activity, critical thinking, problem solving, decision making, collaboration with team, and team communication. The simulationbased learning can be accessed anytime based on individual schedules and requirement until they gained their self-confidence and self-reflection in the simulation laboratory as the safety environment before nursing care practice in the real situation (Khammani, 2014; Sinthuchai \& Ubolwan, 2017; Dleikan, Lakissian, Hani, \& Sharar-Chami, 2020). It will be useful for them to get better understanding their SWOT: Strengths, Weaknesses, Opportunities, and Threats. This is an advantage to improve their nursing care skills and relevant skills in healthcare.

The small sample size and characteristics of nursing students who participated in this study has limited the generalisability of the study findings. The limitation of this study should be considered. Most of the students represented a highest level of nursing education in bachelor's degree that may have limited to represent of the entire population. The sample in this study was the fourth year of nursing students that studies the nursing theories, nursing process, nursing care, and clinical practice in the hospital and communities for maternal and newborn and midwifery both low risk, high risk, and complications during pregnancy, delivery, and postpartum period, which support the sample to gain better their understanding with the patients and their families than lower year of nursing students. Therefore, in the future, this simulation program will be tested the effectiveness and learning achievement in other groups of healthcare students. It also helpful for a nursing instructor to plan the research and development the simulation-based learning for integration within the theoretical and practical section in nursing education and after graduation that help to improve the learner's knowledge, attitude, practical skills, core nursing competencies and self-practice (Rothgeb, 2008; Khammani, 2014; Dleikan, Lakissian, Hani, \& Sharar-Chami, 2020). This study will be use as a good strategy and evidence to develop the simulation-based learning for attachment and engagement the learners. In addition, the simulation program should be concerened the learner's readiness, time, the number of members in a team, and attachtive simulated scenario. It will increase the learning achievement of the nursing students that improve quality of care and safe in the healthcare system.

\section{Conclusion}

The study indicated the simulation-based learning that enhances the core competencies and performances of nursing students for management women with early postpartum hemorrhage as knowledge, potential clinical care skills, and attitude inclusing increasing self-confidence, critical thinking, problem solving, decision making, and collaboration with team and others. It will be useful to implement for nursing care women regarding early postpartum hemorrhage in the real situations and significantly improve the effective learning achievement.

\section{Conflict of interest}

This research was fund from Faculty of Nursing, Naresuan University, Thailand. The funder has no role in the study design, collection, management, analysis or interpretation of data or writing of this report.

\section{Acknowledgement}

The authors would like to thank Associate Professor Chommanard Wannapornsiri, Dean of faculty of Nursing, Naresuan University, Thailand for her kind support and valuable suggestion. This study was fund from Faculty of Nursing, Naresuan University, Thailand. We thank our research team for their kind supports and collaboration and we also thank the subjects for their participation in this study. $\mathrm{d} /$ or publication of this article.

\section{References}

Browne, R.H. (1995). On the use of a pilot sample for sample size determination. Statistics in Medicine, 14(19), 33-40. https://doi. org/10.1002/sim.4780141709

Dleikan, C., Lakissian, L., Hani, S., \& Sharar-Chami, R. (2020). Designing a simulation center: an experimental guide designing a simulation center. Journal of Facilities Management, 18(5). https://doi.org/10.1108/JFM-02-20200011

Eldridge, S.M., Lancaster, G.A., Campbell, M.J., 
Thabane, L., Hopewell, S., Coleman, C.L, et al. (2016). Defining feasibility and pilot studies in preparation for randomised controlled trials: Development of a conceptual framework. PloS ONE, 11(3), e0150205. https://doi.org/10.1371/ journal.pone.0150205

Field, A. (2015). Discovering statistics using IBM SPSS statistics IBM book. SAGE Publications.

Glynn, D. M. (2012). Clinical judgment development using structured classroom reflective practice: A qualitative study. Journal of Nursing Education, 51(3),134-139. https://doi. org/10.3928/01484834-20120127-06

Kanhadilok, S., \& Punsumreung, T. (2016). Simulation based learning: Design for nursing education. Journal of Nursing and Education, 9(1). [In Thai].

Khammani, T. (2014). Teaching science: Knowledge for effective learning process. (21st ed.). Bangkok: Chulalongkorn University Press. [In Thai].

Lancaster, G.A., Dodd, S., Williamson, P.R. (2004). Design and analysis of pilot studies: recommendations for good practice. Journal of Evaluation in Clinical Practice.10(2), 307-312. https://doi.org/10.1111/j..2002.384.doc.x

Lewis, R., Strachan, A., \& Smith, M. M. (2012). Is high fidelity simulation the most effective method for the development of non-technical skills in nursing? A review of the current evidence. The Open Nursing Journal, 6(1), 82-89. https://doi. org/10.2174/1874434601206010082
Mahaprom, T., Chatrung, C., Noparoojjinda, S., Peawnalaw, S., \& Doungkeaw, J. (2019). Development of an instructional model basedon simulation-based learning in nursing care of persons with health problems. Multidisciplinary Journal for Health, 1(2), 47-61. [In Thai].

Murray, S. S., \& McKinny, E. S. (2019). Foundations of maternal-newborn and women's health nursing (7th edition). Saunders Elsevier.

Rothgeb, M.K. (2008). Creating a nursing simulation laboratory: a literature review. Journal of Nursing Education, 47(11), 489-494. https:// doi.org/10.3928/01484834-20081101-06

Sansiriphun, N., \& Baosoung, C. (2017). Nursing and midwifery: women with complications. Chiang Mai: Faculty of Medicine Chiang Mai University. [In Thai].

Sinthuchai, S., \& Ubolwan, K. (2017). Fidelity simulation-based learning: Implementation to learning and teaching management. Journal of The Royal Thai Army Nurses, 18(1). [In Thai].

Suprasert, P., Cheewakriangkrai, C., Tongprasert, F., \& Pansri, T. (2015). Chiang Mai textbook of ob\&gyn: Advanced update. Chiang Mai: Faculty of Medicine Chiang Mai University.

World Health Organization (WHO). (2012). WHO recommendations for the prevention and treatment of postpartum haemorrhage. Geneva: WHO. Retrieved January 20, 2016, from http://www.who.int/iris/ bitstream/10665/75411/1/9789241548502_ eng.pdf 